\title{
Does coracoclavicular augmentation additional to hook plate fixation provide benefits in acute unstable acromioclavicular dislocation? A meta-analysis
}

\author{
Chih-Yao Lee ${ }^{1 \dagger}$, Po-Cheng Chen ${ }^{2,3 \dagger}$, Ying-Chun Liu ${ }^{4}$, Yun-Che Tsai ${ }^{1}$, Pei-Hsi Chou ${ }^{1,5}$, Yin-Chih Fu ${ }^{1,5,6,7}$, \\ Wen-Chih Liu ${ }^{1,5,7^{*}}$ and Jesse Bernard Jupiter ${ }^{8}$
}

\begin{abstract}
Background: Acromioclavicular joint (ACJ) dislocation is a common shoulder injury. In treating acute unstable ACJ dislocation, a hook plate (HP) is a straightforward and popular option for ensuring proper reduction and rigid fixation while promoting AC and coracoclavicular (CC) ligament healing. Surgeons typically remove the HP to prevent subacromial impingement and acromial osteolysis; however, concerns about redislocation after implant removal remain. Therefore, additional CC augmentation may be helpful in combination with HP fixation. The aim of this meta-analysis is to compare the outcomes and complications of HP fixation with or without additional CC augmentation for acute unstable ACJ dislocation.
\end{abstract}

Methods: We searched the PubMed, EMBASE, and Web of Science databases for relevant case-control studies. The primary outcomes were patient-reported outcome measures; the secondary outcomes were pain measured using a visual analog scale (VAS), CC distance (CCD), and complications. Continuous data were assessed using weighted standardized mean differences (SMDs) with 95\% confidence intervals (Cls), and dichotomous data were evaluated with Mantel-Haenszel odds ratio (ORs) with 95\% Cls.

Results: We analyzed one randomized control trial and four case-control studies comparing HP fixation with or without CC augmentation. A total of 474 patients with Rockwood type III or V ACJ dislocation were included. We found no differences in Constant-Murley score (SMD, $-0.58,95 \% \mathrm{Cl}-1.41$ to $0.26 ; P=0.18)$, American Shoulder and Elbow Surgeons score (SMD, $0.21,95 \% \mathrm{Cl}-0.10$ to $0.52 ; P=0.19)$, University of California at Los Angeles shoulder rating scale score $(S M D,-0.02,95 \% \mathrm{Cl}-1.27$ to $1.23 ; P=0.97)$, or VAS pain score $(S M D, 0.36,95 \% \mathrm{Cl}-0.16$ to $0.88 ; P=0.17)$ between groups. The CC augmentation group had lower odds of osteolysis $(\mathrm{OR}, 0.27,95 \% \mathrm{Cl} 0.10$ to $0.74 ; P=0.01)$ and a shorter $C C D(S M D,-0.29,95 \% \mathrm{Cl}-0.57$ to $-0.01 ; P=0.04)$.

Conclusion: HP fixation with CC augmentation is preferable for acute unstable ACJ dislocations. Although CC augmentation did not provide additional benefits related to functional outcomes or pain, it resulted in greater reduction maintenance after implant removal and a $73 \%$ lower risk of acromial osteolysis.

\footnotetext{
*Correspondence: andysirliu@gmail.com

${ }^{\dagger}$ Chih-Yao Lee and Po-Cheng Chen contributed equally to this work.

${ }^{1}$ Department of Orthopedic Surgery, Kaohsiung Medical University Hospital, Kaohsiung Medical University, 807 Kaohsiung, Taiwan

Full list of author information is available at the end of the article
} permits use, sharing, adaptation, distribution and reproduction in any medium or format, as long as you give appropriate credit to the original author(s) and the source, provide a link to the Creative Commons licence, and indicate if changes were made. The images or other third party material in this article are included in the article's Creative Commons licence, unless indicated otherwise in a credit line to the material. If material is not included in the article's Creative Commons licence and your intended use is not permitted by statutory regulation or exceeds the permitted use, you will need to obtain permission directly from the copyright holder. To view a copy of this licence, visit http://creativecommons.org/licenses/by/4.0/. The Creative Commons Public Domain Dedication waiver (http://creativeco mmons.org/publicdomain/zero/1.0/) applies to the data made available in this article, unless otherwise stated in a credit line to the data. 
Trial registration: PROSPERO (CRD42021271118).

Keywords: Acromioclavicular joint dislocation, Acromioclavicular joint separation, Hook plate, Coracoclavicular reconstruction, Coracoclavicular repair, Acromial osteolysis

\section{Background}

Acromioclavicular joint (ACJ) dislocation is a common injury that accounts for $50 \%$ of all sports-related shoulder injuries $[1,2]$. The coracoclavicular (CC) and AC ligaments are the most important anatomical structures for maintaining the stability of the ACJ. Operative management is often indicated for Rockwood type IIIVI ACJ dislocation [3], but operation for type III dislocation remains controversial [4-6].

Various treatment options for acute unstable ACJ dislocation, such as CC fixation (using Bosworth screws, suture anchors, hook plates [HPs], or TightRope) [3, 7-14], AC fixation (using tension band wires, Kirschner wires, or sutures) $[8,15], \mathrm{AC}$ or CC reconstruction, and ligament transfer (Weaver-Dunn procedures) [16], have been investigated [17-22]. However, the optimal treatment for ACJ dislocation is still debated [3, 8, 23, 24]. The clavicle HP is used in one of the most common techniques to promote CC ligament scaring [25-27]. This device has many advantages, including facilitating a more straightforward surgical technique, rigid fixation, and early resumption of normal activities [25-27]. Despite these advantages, the HP should typically be removed after 3 to 6 months to prevent complications such as limited early shoulder motion, subacromial impingement, and acromial osteolysis [28-30]. Nevertheless, HP fixation is a safe and effective option for treating ACJ dislocation [31].

To lower the incidence of $\mathrm{ACJ}$ redislocation and the risk of acromial osteolysis, CC augmentation in conjunction with HP fixation is a reasonable option [27]. The possible benefits of combined HP fixation and CC augmentation include stronger initial fixation and support after removal of the HP. However, this combination's efficacy remains unclear. The aim of this meta-analysis is to compare the outcomes and complications of HP fixation with and without $\mathrm{CC}$ augmentation in acute unstable ACJ dislocation. The primary outcomes were patient-reported outcome measures, and the secondary outcomes were a visual analog scale (VAS) score for pain, radiographically determined $\mathrm{CC}$ distance (CCD), the incidence of acromial osteolysis, and overall complications.

\section{Methods}

\section{Search strategy and inclusion criteria}

We conducted this study in accordance with the Preferred Reporting Items for Systematic Reviews and
Meta-Analyses guidelines [32]. We searched three electronic databases, PubMed, Embase, and Web of Science up to July 27, 2021, using the following search string: (((acromioclavicular joint) OR (AC joint)) AND ((dislocation) OR (separation))) AND ((hook plate)). We reviewed the bibliographies of the resulting trials and related review articles manually for relevant references. Two independent reviewers (YCL and PCC) screened the titles and abstracts and examined the full texts of the eligible articles in detail. A third reviewer resolved any disagreements by making the final decision.

We enrolled any prospective or retrospective casecontrol studies that met the following criteria: (1) a target population comprising patients with acute Rockwood type III, IV, or V ACJ displacement treated with HP fixation; (2) a comparative design with two treatment arms, one of HP fixation only and another of HP fixation with $\mathrm{CC}$ augmentation (CCHP); and (3) clinical outcomes measured at least 1 year after operation. We excluded (1) review articles and (2) duplicate publications. Fig. 1 visualizes the selection process.

\section{Methodological quality assessment}

Two reviewers (YCL and YCT) assessed the quality of the studies independently, and the quality was confirmed by a third reviewer. We assessed the methodological quality of studies by using the Jadad scale for randomized controlled trials (RCTs) [33] and Newcastle-Ottawa scale (NOS) for prospective or retrospective comparative trials [34]. The Jadad scale is a 5-point scale that evaluates the methodologies of RCTs in three domains: randomization ( 2 points), blinding ( 2 points), and account of all patients (1 point) [33]. Higher scores indicate superior methodological quality. The NOS contains nine items measuring three domains: participant selection (four items, maximum of 4 points), comparability (one item, maximum of 2 points), and exposure (three items, maximum of 3 points). The maximal score is 9 points, with higher scores indicating superior methodological quality [34]. Cohen's kappa coefficient was used to measure interrater reliability and to quantify the degree of agreement between the reviewers.

Discrepancies were resolved through discussion under the supervision of the corresponding author. In addition, we attempted to contact the primary authors of the included studies for any missing data. 


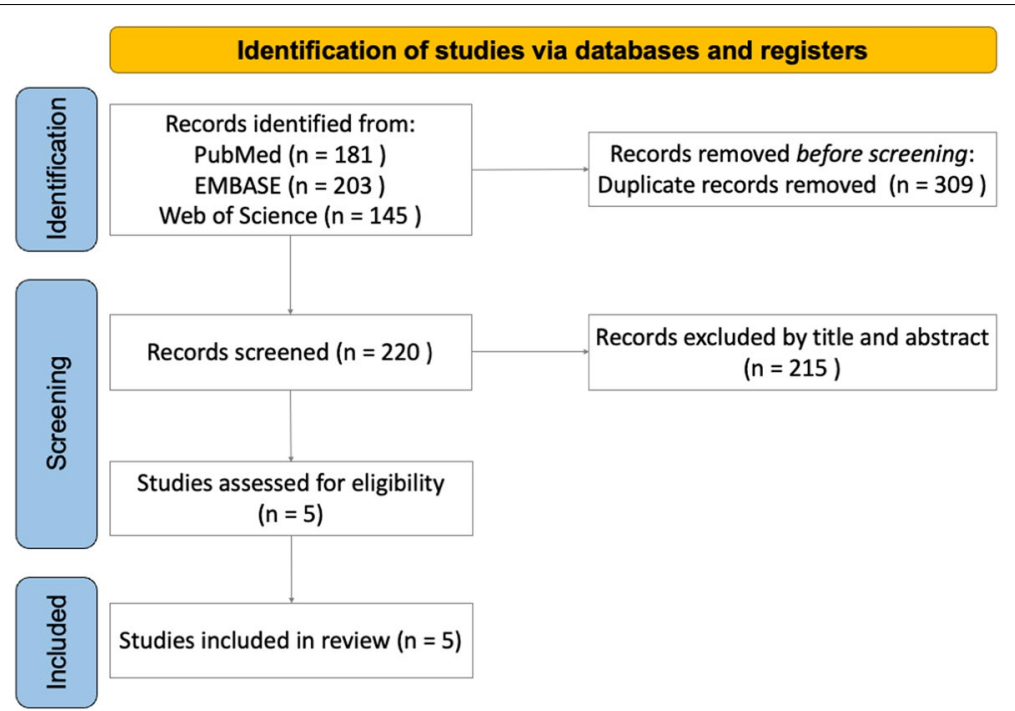

Fig. 1 Preferred Reporting Items for Systematic Reviews and Meta-Analyses flow diagram of study search and screening for inclusion

\section{Data extraction}

Two reviewers (CYL and PCC) independently extracted the following data related to the study characteristics and interventions and then verified the data together: study design, sample size, age distribution, sex distribution, follow-up period, types of $\mathrm{HP}$, and suture used for CC fixation. The primary outcomes were the following patientreported outcome measures: Constant-Murley score (CMS), the American Shoulder and Elbow Surgeons (ASES) shoulder score, and the University of California at Los Angeles (UCLA) shoulder scale score. The secondary outcomes were the VAS (0-10) score for pain, CCD, and complications (e.g., osteolysis, ACJ osteoarthritis, periimplant fracture, and infection).

\section{Meta-analysis methodology}

The senior author (WCL) used Comprehensive MetaAnalysis version 3 (Biostat, Englewood, NJ, USA) to pool the effects of interest from our included studies.

For continuous data (primary outcomes, CCD, and VAS score), we estimated the summary of standardized mean differences (SMDs) and 95\% confidence intervals (CIs). For dichotomous data (complications), we estimated the odds ratio (OR) and 95\% CI. We used the Mantel-Haenszel ( $\mathrm{MH})$ method to estimate the effect size for binary outcomes and the inverse variance method to pool the effect size for continuous results. A negative SMD indicated that CCHP was the more favorable treatment option. ORs of $<1$ and $>1$ respectively indicated CCHP and HP fixation alone to be the preferable treatment option. We used a Cochran Q test to evaluate heterogeneity. A two-tailed $P$ value $<0.01$ was considered statistically significant. We approximated the percentage of variability in the heterogeneity estimation by using $I^{2}$ [35]. We employed subgroup analyses to determine the sources of heterogeneity. We employed random-effects models to calculate all the relationships. We employed Egger test [36] and funnel plots [37] to assess publication bias.

\section{Results}

Literature search and study characteristics

We reviewed the titles and abstracts of 220 unique articles; five articles met the inclusion criteria and were assessed further for eligibility. No studies were excluded on the basis of the eligibility assessment (Fig. 1). Ultimately, we obtained one RCT [38] and four retrospective case-control studies [39-42] for the eventual meta-analysis.

A total of 474 patients were included, and we broke down the numbers of patients, mean ages, and sex ratios of the comparator groups. All studies reported patient sex and age data. Four studies enrolled patients with Rockwood type III or V ACJ dislocation; one study enrolled type $\mathrm{V}$ dislocation only [41]. Two studies enrolled patients who had experienced traumatic injury less than 2 weeks prior to study commencement [39, 41, 42], one enrolled patients who had experienced traumatic injury less than 4 weeks prior to study commencement [40], and one enrolled patients who had experienced traumatic injury less than 6 weeks prior to study commencement [38]. One RCT [38] received Jadad score of 3. Four retrospective case-control studies were evaluated using the NOS; one received a score of 8 [40], and three received 


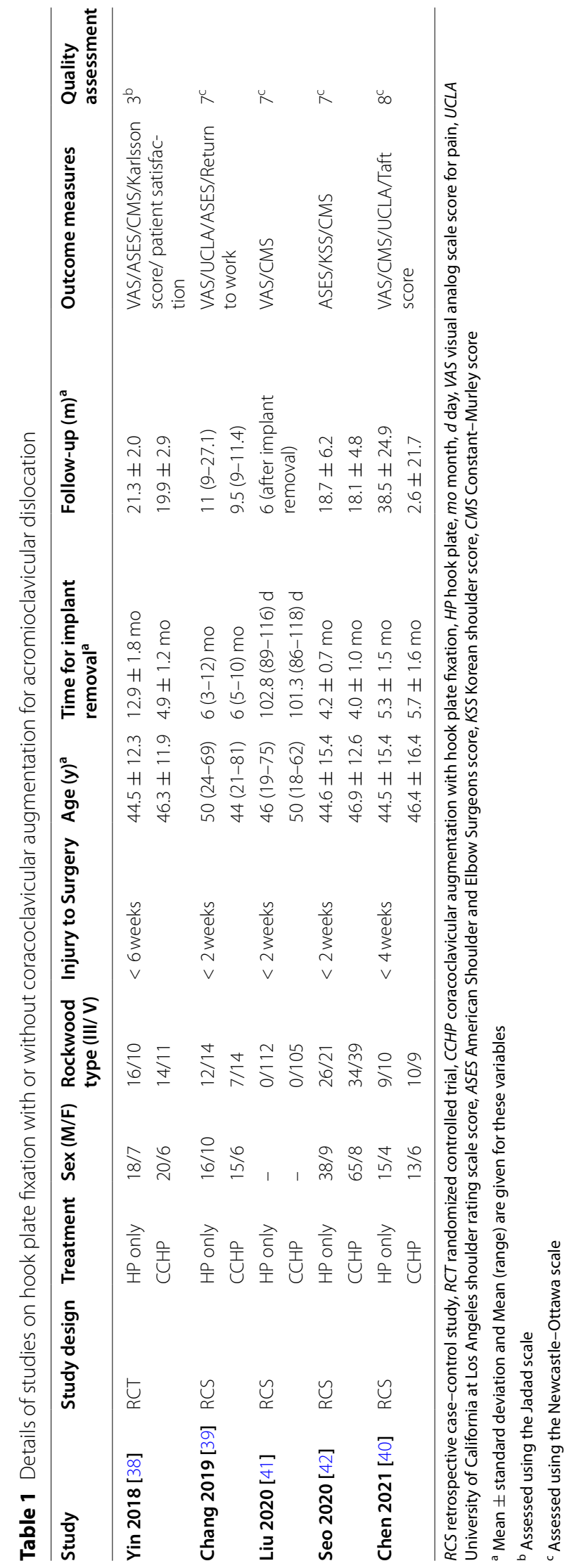


scores of 7 [39, 41, 42]. Table 1 presents the details of each study. The degree of agreement between reviewers on the NOS and Jadad scores is reported in Table 2.

\section{Summary of surgical procedures and postoperative management}

In the HP fixation groups of all included studies, all ACJs underwent debridement before reduction. In two studies, the AC ligament was repaired before placement of the $\mathrm{HP}$ - one with an absorbable suture [38] and the other with tape fixation [39]. The other studies did not mention any repair of the AC ligament [40-42]. After the dislocated ACJ was reduced, the HP was inserted posterior to the $\mathrm{ACJ}$ and fixed the clavicle with screws. In the CCHP group, the ACJs were prepared and reduced as in the HP treatments. The CC augmentation consisted of either repair or reconstruction of the $\mathrm{CC}$ ligament before HP fixation. In one study, the CC ligament was repaired with an absorbable Vicryl No. 1 suture (Ethicon, Cincinnati, $\mathrm{OH}, \mathrm{USA}$ ) [42]. The materials used for $\mathrm{CC}$ augmentation differed. In one study, 6-mm nylon was used to reconstruct the CC ligament through bone tunnel on clavicle [41]; the CC ligament was reconstructed with a sterile polyester surgical suture (Mersilene Polyester Fiber Suture, Ethicon, Cincinnati, OH, USA) in two studies $[39,40]$; one through two tunnels on clavicle [40] and the other make multiple knots at the anterior to the clavicle [39]. One study, double-tunnel CC ligament reconstruction was performed with an autograft harvested

Table 2 Interrater reliability of Newcastle-Ottawa and Jadad scales between two reviewers

\begin{tabular}{|c|c|}
\hline & $\begin{array}{l}\text { Inter-rater reliability } \\
\text { Kappa coefficient }(95 \% \mathrm{Cl})\end{array}$ \\
\hline \multicolumn{2}{|l|}{ Newcastle-Ottawa scale (4 studies) } \\
\hline \multicolumn{2}{|l|}{ Selection } \\
\hline Is the case definition adequate & 1 \\
\hline Representativeness of the cases & 1 \\
\hline Selection of Controls & 1 \\
\hline Definition of Controls & 1 \\
\hline \multicolumn{2}{|l|}{ Comparability } \\
\hline Study control & $0.20(-0.27$ to 0.67$)$ \\
\hline Any additional factor & 1 \\
\hline \multicolumn{2}{|l|}{ Outcome } \\
\hline Assessment of outcome & 1 \\
\hline $\begin{array}{l}\text { Was follow-up long enough for out- } \\
\text { comes to occur }\end{array}$ & 1 \\
\hline Adequacy of follow up of cohorts & $0.50(-0.24$ to 1.00$)$ \\
\hline \multicolumn{2}{|l|}{ Jadad scale (1 study) } \\
\hline Randomization & 1 \\
\hline Blinding & 1 \\
\hline Withdrawal and dropouts & 1 \\
\hline
\end{tabular}

from the lateral half of the short head of the biceps tendon [38]. All HPs were removed after 3 to 6 months of fixation except for those in the HP only group in one study, which were removed after 12.95 months [38].

\section{Patient-reported outcome measures}

No significant differences were identified in CMS $(N=427$; SMD $,-0.58,95 \% \mathrm{CI}-1.41$ to $0.26 ; P=0.18$; Fig. 2a), UCLA score $(N=85$; SMD, $0.02,95 \% \mathrm{CI}-1.23$ to 1.27 ; $P=0.97$; Fig. $2 \mathrm{~b})$, or ASES score $(N=167$; SMD, $-0.21,95 \% \mathrm{CI}-0.52$ to $0.10 ; P=0.19$; Fig. $2 \mathrm{c}$ ). Heterogeneity was present in the CMS $\left(I^{2}=93 \%\right)$ and UCLA score $\left(I^{2}=88 \%\right)$ results but not in the ASES score results $\left(I^{2}=0 \%\right)$.

\section{Pain VAS scores}

VAS pain scores did not differ significantly $(N=354$; SMD, $0.36,95 \%$ CI -0.16 to 0.88 ; $P=0.17$; Fig. 3$)$. Heterogeneity was present in the VAS results $\left(I^{2}=77 \%\right)$.

\section{CCD}

CCD significantly differed between groups $(N=205$; SMD, $-0.29,95 \% \mathrm{CI}-0.57$ to $-0.01 ; P=0.04$; Fig. 4 ), suggesting superior $\mathrm{CCD}$ maintenance in the CCHF group. No heterogeneity was present in the $\mathrm{CCD}$ results $\left(I^{2}=0 \%\right)$.

\section{Complications such as acromial Osteolysis}

All complications in each included study are listed in Table 3. Among all complications, we found significantly greater odds of acromial osteolysis $(N=474$; odds ratio (OR), $0.27,95 \%$ CI 0.10 to $0.74 ; P=0.01$; Fig. 5 ) for the HP only group. Heterogeneity was present in the acromial osteolysis results $\left(I^{2}=76 \%\right)$. Comparing only the studies with early implant removal ( $<6$ months) in both the HP only and CCHP groups [39-42], we still found more acromial osteolysis in the HP only group $(N=420$; MH OR, 0.34, 95\% CI 0.13 to $0.92 ; P=0.03$ ).

\section{Subgroup analysis}

We subdivided CC augmentation into CC ligament reconstruction [38-41] and CC ligament repair [42] groups. CCD did not differ between groups $(\mathrm{Q}=1.27$, $d f=1, P=0.259$ ). Although the incidence of acromial osteolysis differed significantly from that of HP fixation alone $(\mathrm{Q}=14.3, d f=1, P<0.01)$, no difference was found between the $C C$ reconstruction and repair subgroups $(\mathrm{Q}=2.49, d f=3, P=0.48$; Fig. 6 ).

\section{Publication Bias}

Because at least three of the studies could run publication bias procedures for an outcome, we could not evaluate publication bias for the UCLA or ASES score The Egger 
(A)

\begin{tabular}{lrrrr} 
Study name & \multicolumn{4}{c}{ Statistics for each study } \\
\cline { 1 - 4 } & $\begin{array}{c}\text { Std diff } \\
\text { in means }\end{array}$ & $\begin{array}{c}\text { Lower } \\
\text { limit }\end{array}$ & $\begin{array}{c}\text { Upper } \\
\text { limit }\end{array}$ & p-Value \\
Chen 2021 & 0.085 & -0.552 & 0.721 & 0.794 \\
Liu 2020 & -0.077 & -0.344 & 0.189 & 0.570 \\
Seo 2020 & 0.020 & -0.347 & 0.386 & 0.916 \\
Yin 2018 & -2.541 & -3.272 & -1.810 & 0.000 \\
& -0.576 & -1.410 & 0.258 & 0.176
\end{tabular}

(B)

\begin{tabular}{lrrrrr} 
Study name & \multicolumn{4}{c}{ Statistics for each study } \\
\cline { 3 - 5 } & $\begin{array}{c}\text { Std diff } \\
\text { in means }\end{array}$ & $\begin{array}{c}\text { Lower } \\
\text { limit }\end{array}$ & $\begin{array}{c}\text { Upper } \\
\text { limit }\end{array}$ & p-Value \\
Chang 2019 & -0.609 & -1.197 & -0.021 & 0.042 \\
Chen 2021 & 0.668 & 0.015 & 1.322 & 0.045 \\
& 0.021 & -1.230 & 1.273 & 0.973
\end{tabular}

(C)

\begin{tabular}{lrrrr} 
Study name & \multicolumn{4}{c}{ Statistics for each study } \\
\cline { 1 - 4 } & $\begin{array}{c}\text { Std diff } \\
\text { in means }\end{array}$ & $\begin{array}{c}\text { Lower } \\
\text { limit }\end{array}$ & $\begin{array}{c}\text { Upper } \\
\text { limit }\end{array}$ & p-Value \\
Chang 2019 & -0.457 & -1.039 & 0.125 & 0.124 \\
Seo 2020 & -0.108 & -0.474 & 0.259 & 0.565 \\
& -0.207 & -0.517 & 0.104 & 0.191
\end{tabular}

\section{Std diff in means and $95 \% \mathrm{Cl}$}

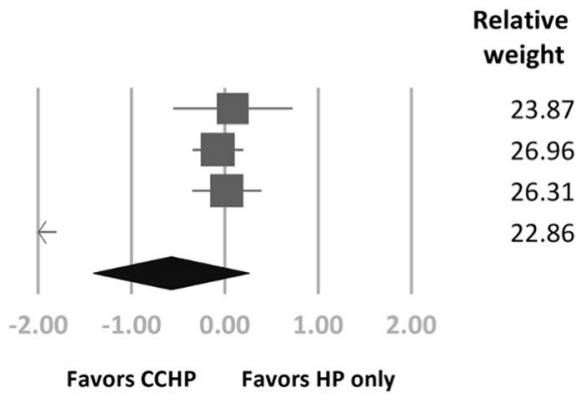

Std diff in means and $95 \% \mathrm{Cl}$

Relative weight

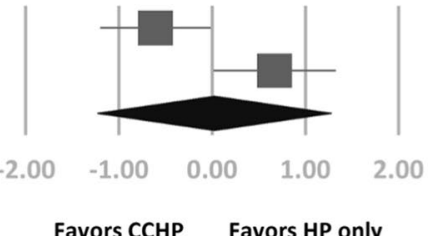

50.65

49.35

Std diff in means and $95 \% \mathrm{Cl}$

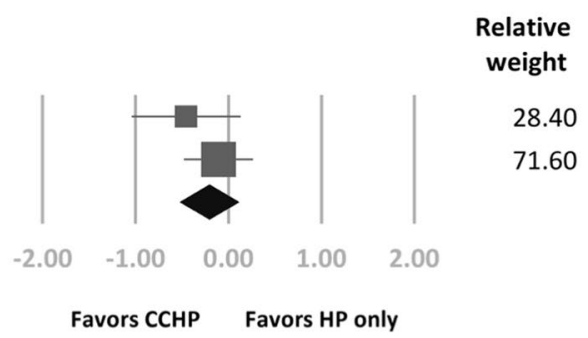

Fig. 2 Forest plots of the weighted standardized mean differences in (A) Constant-Murley score, (B) University of California at Los Angeles shoulder scale score, and (C) American Shoulder and Elbow Surgeons score between treatment arms

\begin{tabular}{|lrrrr} 
Study name & \multicolumn{4}{c}{ Statistics for each study } \\
\cline { 1 - 4 } & $\begin{array}{c}\text { Std diff } \\
\text { in means }\end{array}$ & $\begin{array}{c}\text { Lower } \\
\text { limit }\end{array}$ & $\begin{array}{c}\text { Upper } \\
\text { limit }\end{array}$ & $p$-Value \\
Chang 2019 & -0.304 & -0.883 & 0.274 & 0.303 \\
Chen 2021 & 0.043 & -0.593 & 0.679 & 0.895 \\
Liu 2020 & -0.049 & -0.315 & 0.218 & 0.720 \\
Yin 2018 & -1.206 & -1.797 & -0.615 & 0.000 \\
& -0.359 & -0.877 & 0.159 & 0.175
\end{tabular}

\section{Std diff in means and $95 \% \mathrm{Cl}$}

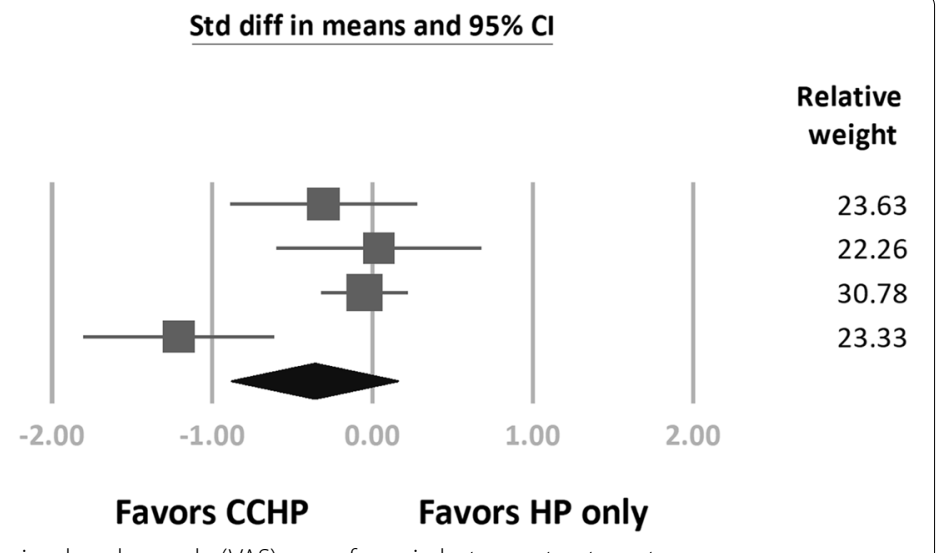

Fig. 3 Forest plots of weighted standardized mean differences in visual analog scale (VAS) score for pain between treatment arms 


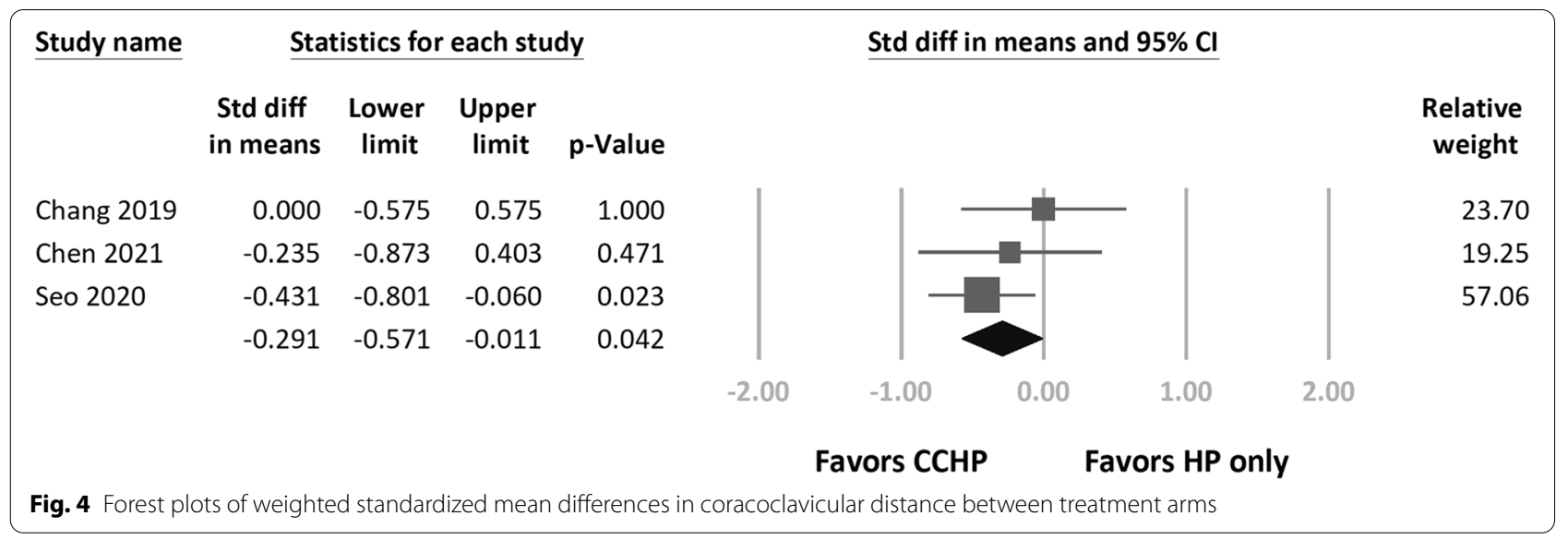

Table 3 Details of complications in each study

\begin{tabular}{lll}
\hline Study & Complications & \\
\cline { 2 - 3 } & CCHP & HP only \\
\hline Yin $\mathbf{2 0 1 8}$ & Acromial osteolysis (0/26) & Acromial osteolysis (12/25) \\
Chang $\mathbf{2 0 1 9}$ & Acromial osteolysis (5/21) & Acromial osteolysis (15/26) \\
& ACJ arthrosis (3/21) & ACJ arthrosis (8/26) \\
& & Superficial wound infection (1/26) \\
Liu $\mathbf{2 0 2 0}$ & Acromial osteolysis (25/105) & Acromial osteolysis (65/112) \\
& Superficial wound infection (2/105) & Peri-implant fracture (8/112) \\
Seo $\mathbf{2 0 2 0}$ & Peri-implant fracture (1/105) & \\
& Acromial osteolysis (32/73) & Acromial osteolysis (19/47) \\
Chen $\mathbf{2 0 2 1}$ & ACJ arthrosis (16/73) & ACJ arthrosis (12/47) \\
& Stiffness before implants removal (25/73) & Stiffness before implants removal (16/47) \\
\hline
\end{tabular}

CCHP coracoclavicular augmentation and hook plate fixation, $H P$ hook plate, $A C J$ acromioclavicular joint

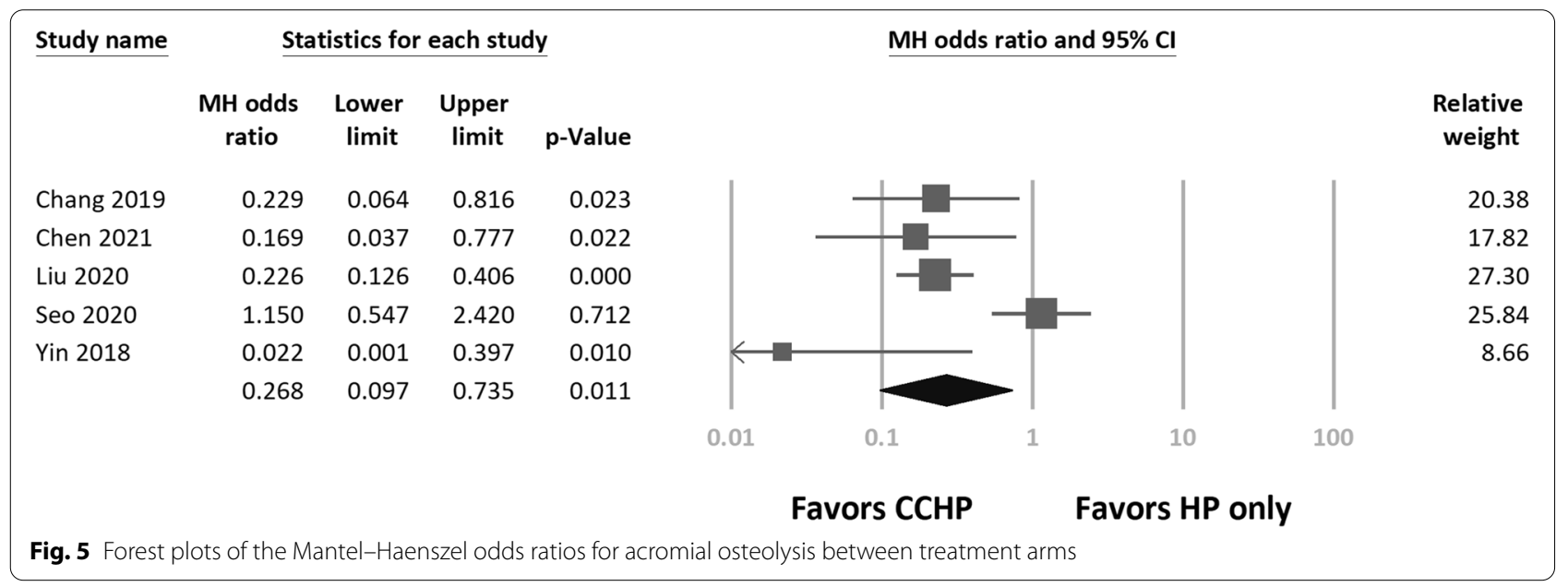




\begin{tabular}{|llllll} 
Study name & Subgroup within study & \multicolumn{5}{c}{\begin{tabular}{c} 
Statistics for each study \\
\cline { 3 - 6 }
\end{tabular}} & & $\begin{array}{c}\text { Odds } \\
\text { ratio }\end{array}$ & $\begin{array}{c}\text { Lower } \\
\text { limit }\end{array}$ & $\begin{array}{l}\text { Upper } \\
\text { limit }\end{array}$ & p-Value \\
Chang 2019 & CC reconstruction & 0.229 & 0.064 & 0.816 & 0.023 \\
Chen 2021 & CC reconstruction & 0.169 & 0.037 & 0.777 & 0.022 \\
Liu 2020 & CC reconstruction & 0.226 & 0.126 & 0.406 & 0.000 \\
Yin 2018 & CC reconstruction & 0.022 & 0.001 & 0.397 & 0.010 \\
& & 0.205 & 0.125 & 0.336 & 0.000 \\
Seo 2020 & CC repair & 1.150 & 0.547 & 2.420 & 0.712 \\
& & 1.150 & 0.547 & 2.420 & 0.712
\end{tabular}

test revealed no significant publication bias for the CMS, VAS, CCD, or acromial osteolysis measures (Table 4); the funnel plots for the CMS, VAS, CCD, and acromial osteolysis measures are symmetric (Fig. 7).

\section{Discussion}

This meta-analysis included five case-control studies enrolling patients with acute Rockwood type III or V ACJ dislocation and comparing HP fixation with and without $\mathrm{CC}$ augmentation. The $\mathrm{CC}$ augmentation group consisted of patients who had undergone CC ligament repair or CC reconstruction with artificial surgical tape or autograft. We found that CCHP showed no advantage over HP alone in functional outcomes or pain; however, CCHP resulted in superior CCD maintenance and a lower incidence of acromial osteolysis.

Acromial osteolysis is one of the most common complications of HP fixation for ACJ dislocation treatment and is caused by the high pressure between the acromion and hook [43]. Acromial osteolysis may further result in chronic shoulder pain and impaired functional outcomes $[18,30]$. In the HP only group, the stability of the ACJ relied mainly on the scar tissue at the base of the CC ligament. However, such scar tissue can rupture easily, resulting in redislocation under an uneven stress distribution. Therefore, concomitant CC augmentation to share the load from the acromion to the coracoid and clavicle is a

Table 4 Egger test results for each outcome

\begin{tabular}{llll}
\hline & $\boldsymbol{t}$-value & $\boldsymbol{d f}$ & $\boldsymbol{P}$ value \\
\hline CMS & 1.15 & 2 & 0.37 \\
VAS & 0.89 & 2 & 0.47 \\
CCD & 1.40 & 1 & 0.39 \\
Acromial osteolysis & 0.80 & 3 & 0.48
\end{tabular}

CMS Constant-Murley score, VAS visual analog scale score for pain, CCD

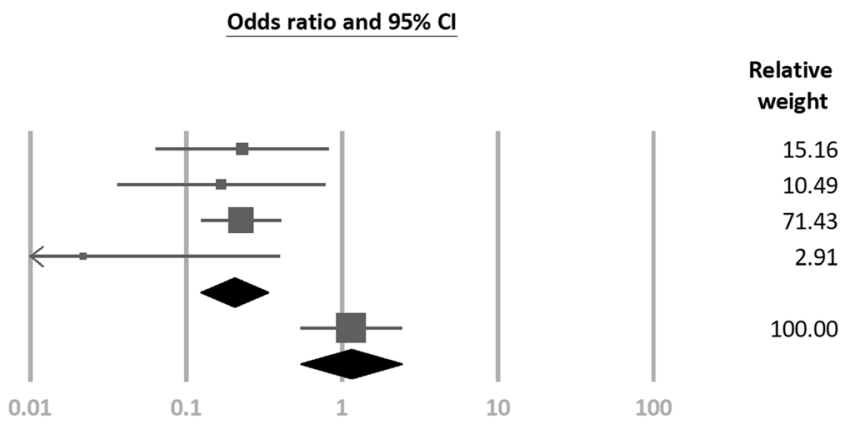

Favors CCHP Favors HP only eight

5.16

2.91

100.00

CC) reconstruction and CC repair viable option. A shorter CCD implies superior maintenance of AC reduction after implant removal in CCHP group. However, the CCHP group did not achieve more favorable functional outcomes and lower pain scores. The patient-reported outcome measures were physical function, psychosocial issues, and quality of life [44]. Therefore, superior CCD maintenance does not necessarily lead to superior patient-reported outcomes; this result is consistent with that of a previous study [45].

Heterogeneity was identified in CMSs $\left(I^{2}=93 \%\right)$, UCLA scores $\left(I^{2}=88 \%\right)$, VAS scores $\left(I^{2}=77 \%\right)$, and osteolysis incidence rates $\left(I^{2}=76 \%\right)$. This heterogeneity might be attributable to several factors, such as the intervals between injury and surgery, $\mathrm{CC}$ augmentation methods, and HP removal time. All the studies included patients with acute unstable ACJ dislocation; however, the rates of injury after trauma varied. The AC and CC ligaments are considered to lose their potential to heal by 3 weeks after trauma $[46,47]$, and the definition of chronic ACJ dislocation is injury persisting for more than 6 weeks after trauma [48]. The definition of such injuries between 3 to 6 weeks after trauma is uncertain. One of the included studies enrolled patients who had experienced traumatic injury less than 4 weeks prior to study commencement [40], and one enrolled patients who had experienced traumatic injury less than 6 weeks prior to study commencement [38]. The other studies enrolled patients who had experienced traumatic injury less than 2 weeks prior to study commencement [39, 41, 42]. Due to the limited number of included studies, we could not perform subgroup analysis to eliminate the heterogeneity in the interval between injury and surgery.

$\mathrm{CC}$ augmentation can be performed through CC ligament repair or reconstruction. Four studies [38-41] 

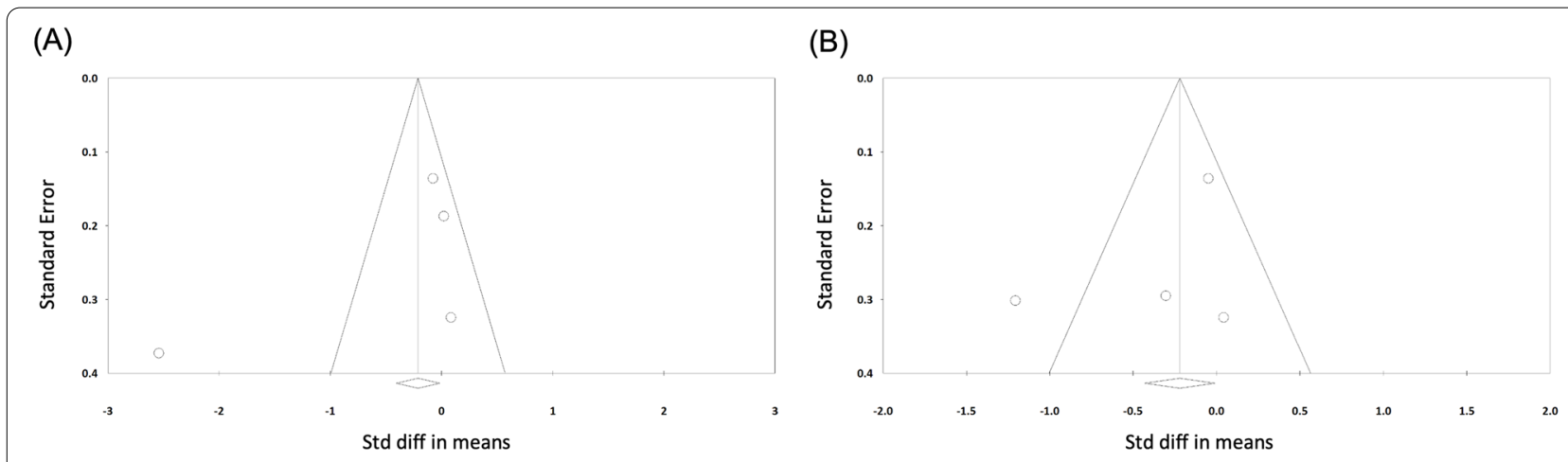

(C)

(D)
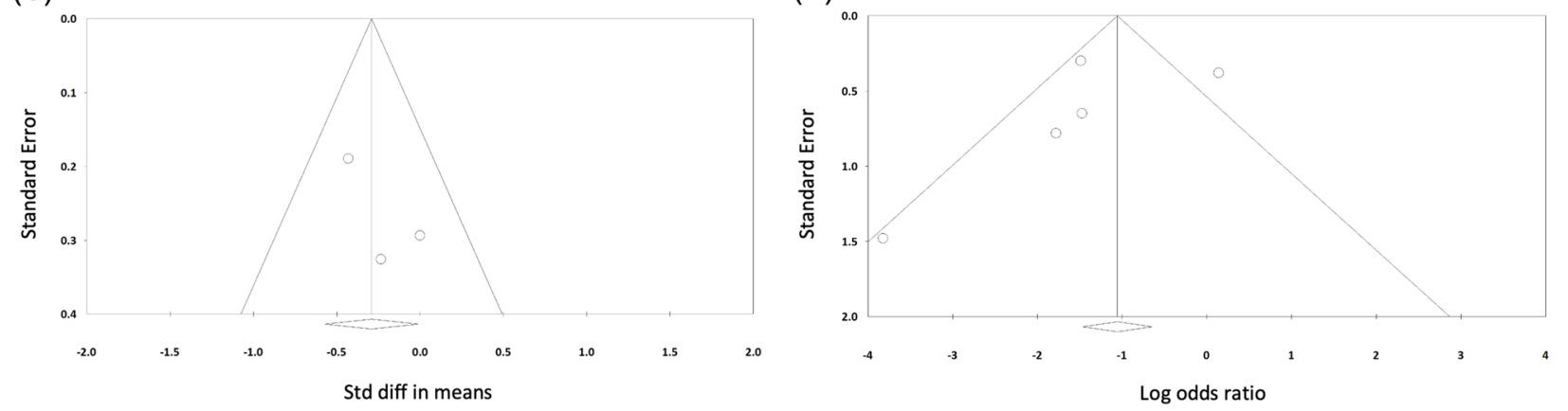

Fig. 7 Funnel plots for (A) Constant-Murley score, (B) visual analog scale score, (C) coracoclavicular distance, and (D) incidence of acromial osteolysis measures

reported on $\mathrm{CC}$ ligament reconstruction; the other reported on CC ligament repair [42]. In subgroup analysis, CC ligament reconstruction was associated with a lower incidence of osteolysis than HP alone, but CC ligament repair was not. We found a significant difference between the subgroup of CC ligament reconstruction and $C C$ repair $(\mathrm{Q}=14.3, P<0.01)$. In addition, we found no differences within the $\mathrm{CC}$ reconstruction group, which implied that suture tape and autologous tendon result in a similar acromion load-sharing effect and reduce the odds of osteolysis. However, we found no difference between groups in $\mathrm{CCD}(\mathrm{Q}=1.27$, $P=0.259$ ). Thus, both $C C$ ligament repair and reconstruction for CCHP can result in superior CCD maintenance than HP alone can.

The CCHP group had 73\% less acromial osteolysis than the HP only group. In one study [38], the implants in the HP only group were removed after 12.9 months, which is over 6 months longer than the period used by other the HP only groups. The different duration of HP fixation might have confounded the results regarding acromial osteolysis. Therefore, we compared only the studies with similar implant removal times between the two groups [39-42]. We found that the CCHP group was still $66 \%$ less likely to develop acromial osteolysis.
Some limitations in this study were as follows. This meta-analysis comprised only one RCT and four retrospective, nonrandomized case-control studies. We should consider potential selection bias in retrospective studies; however, the characteristics of the included patients were similar between the two groups. In addition, measurement bias existed, especially in those studies in which CC reconstruction was performed with a transosseous tunnel in the clavicle. Due to few included studies and short-term follow-ups, we could not perform subgroup analysis to determine the heterogeneity of each outcome.

\section{Conclusion}

On the basis of our analytical results, we favor additional $\mathrm{CC}$ augmentation in combination with HP fixation for treating acute and unstable ACJ dislocations. Although no superiority was demonstrated in functional outcomes or pain, additional CC augmentation resulted in superior reduction maintenance after implant removal and a 73\% lower risk of acromial osteolysis. We recommend further research target patients prone to acromial osteolysis and monitor their long-term functional and clinical outcomes to validate our findings. 


\section{Abbreviations}

ASES: American Shoulder and Elbow Surgeons score; CC: Coracoclavicular; CCD: Coracoclavicular distance; CCHP: Coracoclavicular augmentation with hook plate fixation; Cl: Confidence interval; CMS: Constant-Murley score; HP: Hook plate; MH: Mantel-Haenszel; OR: Odds ratio; SMD: Standardized mean difference; UCLA: University of California at Los Angeles shoulder rating scale.

\section{Authors' contributions}

Each author is expected to have made substantial contributions to the conception. CYL and WCL designed of the work; PHC and YCF did the project coordination; YCL, PCC, YCT and WCL made the data acquisition and analysis; WCL made the data interpretation; CYL and PCC have drafted the work; WCL and JBJ substantively revised it. The author(s) read and approved the final manuscript.

\section{Funding}

This work was supported by the Ministry of Science and Technology, Taiwan (grant ID: MOST 109-2314-B-182A-171) and Chang Gung Memorial Hospital (grant ID: NMRPG8K0241).

\section{Availability of data and materials}

The datasets used/or analyzed during the current study are available from the corresponding author on reasonable request.

\section{Declarations}

Ethics approval and consent to participate

Not applicable.

\section{Consent for publication}

Not applicable.

\section{Competing interests}

The authors declared no potential conflicts of interest with respect to the research, authorship, and/or publication of this article.

\section{Author details}

${ }^{1}$ Department of Orthopedic Surgery, Kaohsiung Medical University Hospital, Kaohsiung Medical University, 807 Kaohsiung, Taiwan. ${ }^{2}$ Department of Physical Medicine and Rehabilitation, Kaohsiung Chang Gung Memorial Hospital, College of Medicine, Chang Gung University, Kaohsiung, Taiwan. ${ }^{3}$ Department of Public Health, College of Medicine, National Cheng Kung University, Tainan, Taiwan. ${ }^{4}$ School of Post-Baccalaureate Medicine, College of Medicine, Kaohsiung Medical University, Kaohsiung, Taiwan. ${ }^{5}$ Ph.D Program in Biomedical Engineering, College of Medicine, Kaohsiung Medical University, Kaohsiung, Taiwan. ${ }^{6}$ Department of Orthopedic surgery, Kaohsiung Municipal Ta-Tung Hospital, Kaohsiug Medical University, Kaohsiung, Taiwan. ${ }^{7}$ Department of Orthopedic Surgery, Kaohsiung Municipal Siaogang Hospital, Kaohsiung Medical University Hospital, Kaohsiung, Taiwan. ${ }^{8}$ Hand and Arm center, Department of Orthopedic surgery, Massachusetts General Hospital, Boston, MA, USA.

\section{Received: 2 September 2021 Accepted: 22 February 2022} Published online: 04 March 2022

\section{References}

1. Willimon SC, Gaskill TR, Millett PJ. Acromioclavicular joint injuries: anatomy, diagnosis, and treatment. Phys Sportsmed. 2011;39(1):116-22. https://doi.org/10.3810/psm.2011.02.1869.

2. McKee MD, Rudzki JR, Gamradt S, Matava MJ. Clavicle trauma: from acromioclavicular joint injuries to distal clavicle fractures and midshaft fractures in contact athletes. Instr Course Lect. 2019;68:41-52.

3. Gowd AK, Liu JN, Cabarcas BC, Cvetanovich GL, Garcia GH, Manderle BJ, et al. Current concepts in the operative management of acromioclavicular dislocations: a systematic review and meta-analysis of operative techniques. Am J Sports Med. 2019;47(11):2745-58. https://doi.org/10. $1177 / 0363546518795147$.

4. Beitzel K, Mazzocca AD, Bak K, Itoi E, Kibler WB, Mirzayan R, et al. ISAKOS upper extremity committee consensus statement on the need for diversification of the Rockwood classification for acromioclavicular joint injuries. Arthroscopy. 2014;30(2):271-8. https://doi.org/10.1016/j.arthro. 2013.11.005.

5. Modi CS, Beazley J, Zywiel MG, Lawrence TM, Veillette CJ. Controversies relating to the management of acromioclavicular joint dislocations. Bone Joint J. 2013;95-B(12):1595-602. https://doi.org/10.1302/0301-620X. 95B12.31802.

6. Smith TO, Chester R, Pearse EO, Hing CB. Operative versus non-operative management following Rockwood grade III acromioclavicular separation: a meta-analysis of the current evidence base. J Orthop Traumatol. 2011;12(1):19-27. https://doi.org/10.1007/s10195-011-0127-1.

7. Cetinkaya E, Arikan Y, Beng K, Mutlu H, Yalcinkaya M, Uzumcugil O. Bosworth and modified phemister techniques revisited. A comparison of intraarticular vs extraarticular fixation methods in the treatment of acute Rockwood type III acromioclavicular dislocations. Acta Orthop Traumatol Turc. 2017;51(6):455-8. https://doi.org/10.1016/j.aott.2017.09.002.

8. Liu T, Bao FL, Jiang T, Ji GW, Li JM, Jerosch J. Acromioclavicular joint separation: repair through suture anchors for coracoclavicular ligament and nonabsorbable suture fixation for acromioclavicular joint. Orthop Surg. 2020;12(5):1362-71. https://doi.org/10.1111/os.12771.

9. Weitzman G. Treatment of acute acromioclavicular joint dislocation by a modified Bosworth method. Report on twenty-four cases. J Bone Joint Surg Am. 1967;49(6):1167-78.

10. Tsou PM. Percutaneous cannulated screw coracoclavicular fixation for acute acromioclavicular dislocations. Clin Orthop Relat Res. 1989;243:112-21.

11. Hessmann M, Gotzen L, Gehling H. Acromioclavicular reconstruction augmented with polydioxanonsulphate bands. Surgical technique and results. Am J Sports Med. 1995;23(5):552-6. https://doi.org/10.1177/ 036354659502300506.

12. Morrison DS, Lemos MJ. Acromioclavicular separation. Reconstruction using synthetic loop augmentation. Am J Sports Med. 1995;23(1):105-10. https://doi.org/10.1177/036354659502300118

13. Sim E, Schwarz N, Höcker K, Berzlanovich A. Repair of complete acromioclavicular separations using the acromioclavicular-hook plate. Clin Orthop Relat Res. 1995;314:134-42.

14. Breslow MJ, Jazrawi LM, Bernstein AD, Kummer FJ, Rokito AS. Treatment of acromioclavicular joint separation: suture or suture anchors? J Shoulder Elb Surg. 2002;11(3):225-9. https://doi.org/10.1067/mse.2002.123904.

15. Biz C, Berizzi A, Cappellari A, Crimi A, Tamburin S, lacobellis C. The treatment of acute rockwood type III acromio-clavicular joint dislocations by two different surgical techniques. Acta Biomed. 2015;86(3):251-9.

16. Costic RS, Labriola JE, Rodosky MW, Debski RE. Biomechanical rationale for development of anatomical reconstructions of coracoclavicular ligaments after complete acromioclavicular joint dislocations. Am J Sports Med. 2004;32(8):1929-36.https://doi.org/10.1177/0363546504264637.

17. Struhl S, Wolfson TS. Continuous loop double Endobutton reconstruction for Acromioclavicular joint dislocation. Am J Sports Med. 2015:43(10):2437-44 https://doi.org/10.1177/0363546515596409.

18. Wang G, Xie R, Mao T, Xing S. Treatment of AC dislocation by reconstructing CC and AC ligaments with allogenic tendons compared with hook plates. J Orthop Surg Res. 2018;13(1):175. https://doi.org/10.1186/ s13018-018-0879-x.

19. Beitzel K, Obopilwe E, Apostolakos J, Cote MP, Russell RP, Charette R, et al. Rotational and translational stability of different methods for direct acromioclavicular ligament repair in anatomic acromioclavicular joint reconstruction. Am J Sports Med. 2014;42(9):2141-8. https://doi.org/10. 1177/0363546514538947

20. Izadpanah K, Jaeger M, Ogon P, Sudkamp NP, Maier D. Arthroscopically assisted reconstruction of acute Acromioclavicular joint dislocations: anatomic AC ligament reconstruction with protective internal bracing-the "AC-RecoBridge" technique. Arthrosc Tech. 2015;4(2):e153-61. https://doi. org/10.1016/j.eats.2015.01.012.

21. Saier T, Venjakob AJ, Minzlaff P, Fohr $P$, Lindell F, Imhoff $A B$, et al., Value of additional acromioclavicular cerclage for horizontal stability in complete acromioclavicular separation: a biomechanical study. Knee Surg Sports 
Traumatol Arthrosc. 2015; 23(5):1498-505. https://doi.org/10.1007/ s00167-014-2895-7.

22. Weaver JK and Dunn HK, Treatment of acromioclavicular injuries, especially complete acromioclavicular separation. J Bone Joint Surg Am. 1972;54(6):1187-94.

23. Arirachakaran A, Boonard M, Piyapittayanun P, Kanchanatawan W, Chaijenkij K, Prommahachai A, et al. Post-operative outcomes and complications of suspensory loop fixation device versus hook plate in acute unstable acromioclavicular joint dislocation: a systematic review and meta-analysis. J Orthop Traumatol. 2017;18(4):293-304. https://doi.org/ 10.1007/s10195-017-0451-1.

24. Saccomanno MF, Sircana G, Cardona V, Vismara V, Scaini A, Salvi AG, et al. Biologic and synthetic ligament reconstructions achieve better functional scores compared to osteosynthesis in the treatment of acute acromioclavicular joint dislocation. Knee Surg Sports Traumatol Arthrosc. 2021;29(7):2175-93. https://doi.org/10.1007/s00167-020-06217-9.

25. von Heideken J, Bostrom Windhamre H, Une-Larsson V, Ekelund A. Acute surgical treatment of acromioclavicular dislocation type $V$ with a hook plate: superiority to late reconstruction. J Shoulder Elb Surg. 2013;22(1):917. https://doi.org/10.1016/j.jse.2012.03.003.

26. Di Francesco A, Zoccali C, Colafarina O, Pizzoferrato R, Flamini S. The use of hook plate in type III and $\mathrm{V}$ acromio-clavicular Rockwood dislocations: clinical and radiological midterm results and MRI evaluation in 42 patients. Injury. 2012;43(2):147-52. https://doi.org/10.1016/j.injury.2011. 04.002.

27. Kumar N, Sharma V. Hook plate fixation for acute acromioclavicular dislocations without coracoclavicular ligament reconstruction: a functional outcome study in military personnel. Strategies Trauma Limb Reconstr. 2015;10(2):79-85. https://doi.org/10.1007/s11751-015-0228-0.

28. Eschler A, Gradl G, Gierer P, Mittlmeier T, Beck M. Hook plate fixation for acromioclavicular joint separations restores coracoclavicular distance more accurately than PDS augmentation, however presents with a high rate of acromial osteolysis. Arch Orthop Trauma Surg. 2012;132(1):33-9. https://doi.org/10.1007/s00402-011-1399-x.

29. Yoon JP, Lee BJ, Nam SJ, Chung SW, Jeong WJ, Min WK, et al. Comparison of results between hook plate fixation and ligament reconstruction for acute unstable acromioclavicular joint dislocation. Clin Orthop Surg. 2015;7(1):97-103. https://doi.org/10.4055/cios.2015.7.1.97.

30. Hoffler CE, Karas SG. Transacromial erosion of a locked subacromial hook plate: case report and review of literature. J Shoulder Elb Surg. 2010;19(3):e12-5. https://doi.org/10.1016/j.jse.2009.10.019.

31. Stein T, Müller D, Blank M, Reinig Y, Saier T, Hoffmann R, et al. Stabilization of acute high-grade Acromioclavicular joint separation: a prospective assessment of the Clavicular hook plate versus the double double-button suture procedure. Am J Sports Med. 2018;46(11):2725-34. https://doi.org/ $10.1177 / 0363546518788355$.

32. Page MJ, McKenzie JE, Bossuyt PM, Boutron I, Hoffmann TC, Mulrow CD, et al. The PRISMA 2020 statement: an updated guideline for reporting systematic reviews. BMJ. 2021;372:n71. https://doi.org/10.1136/bmj.n71.

33. Jadad AR, Moore RA, Carroll D, Jenkinson C, Reynolds DJ, Gavaghan DJ, et al. Assessing the quality of reports of randomized clinical trials: is blinding necessary? Control Clin Trials. 1996;17(1):1-12. https://doi.org/10. 1016/0197-2456(95)00134-4.

34. Stang A. Critical evaluation of the Newcastle-Ottawa scale for the assessment of the quality of nonrandomized studies in meta-analyses. Eur J Epidemiol. 2010;25(9):603-5. https://doi.org/10.1007/s10654-010-9491-z.

35. JJ, D., H. JPT, and A. DG. Cochrane handbook for systematic reviews of interventions 10.10.2. 2nd ed. Chichester (UK): John Wiley \& Sons; 2019.

36. Peters JL, Sutton AJ, Jones DR, Abrams KR, Rushton L. Comparison of two methods to detect publication bias in meta-analysis. JAMA. 2006;295(6):676-80. https://doi.org/10.1001/jama.295.6.676.

37. Sterne JA, Egger M. Funnel plots for detecting bias in meta-analysis: guidelines on choice of axis. J Clin Epidemiol. 2001;54(10):1046-55. https://doi.org/10.1016/s0895-4356(01)00377-8.

38. Yin J, Yin Z, Gong G, Zhu C, Sun C, Liu X. Comparison of hook plate with versus without double-tunnel coracoclavicular ligament reconstruction for repair of acute acromioclavicular joint dislocations: a prospective randomized controlled clinical trial. Int J Surg. 2018;54(Pt A):18-23. https:// doi.org/10.1016/j.ijsu.2018.04.017.

39. Chang HM, Hong CK, Su WR, Wang TH, Chang CW, Tai TW. Comparison of clavicular hook plate with and without coracoclavicular suture fixation for acute acromioclavicular joint dislocation. Acta Orthop Traumatol Turc. 2019;53(6):408-13. https://doi.org/10.1016/j.aott.2019.08.002.

40. Chen YT, Wu KT, Jhan SW, Hsu SL, Liu HC, Wang CJ, et al. Is coracoclavicular reconstruction necessary in hook plate fixation for acute unstable acromioclavicular dislocation? BMC Musculoskelet Disord. 2021;22(1):127. https://doi.org/10.1186/s12891-021-03978-3.

41. Liu CT, Yang TF. Hook plate with or without coracoclavicular ligament augmentation in the treatment of acute acromioclavicular separation. BMC Musculoskelet Disord. 2020;21(1):701. https://doi.org/10.1186/ s12891-020-03726-Z.

42. Seo JB, Kim SJ, Ham HJ, Yoo JS. Comparison between hook plate fixation with and without coracoclavicular ligament suture for acute acromioclavicular joint dislocations. J Orthop Surg (Hong Kong). 2020;28(1):2309499020905058. https://doi.org/10.1177/2309499020 905058.

43. Arrigoni P, Brady PC, Zottarelli L, Barth J, Narbona P, Huberty D, et al. Associated lesions requiring additional surgical treatment in grade 3 acromioclavicular joint dislocations. Arthroscopy. 2014;30(1):6-10. https:// doi.org/10.1016/j.arthro.2013.10.006.

44. Schmidt S, Ferrer M, Gonzalez M, Gonzalez N, Valderas JM, Alonso J, et al. Evaluation of shoulder-specific patient-reported outcome measures: a systematic and standardized comparison of available evidence. J Shoulder Elb Surg. 2014;23(3):434-44. https://doi.org/10.1016/j.jse.2013.09.029.

45. Shin SJ, Kim NK. Complications after arthroscopic coracoclavicular reconstruction using a single adjustable-loop-length suspensory fixation device in acute acromioclavicular joint dislocation. Arthroscopy. 2015;31(5):816-24. https://doi.org/10.1016/j.arthro.2014.11.013.

46. Cisneros LN, Reiriz JS. Management of chronic unstable acromioclavicular joint injuries. J Orthop Traumatol. 2017;18(4):305-18. https://doi.org/10. 1007/s10195-017-0452-0.

47. Weinstein DM, McCann PD, Mcllveen SJ, Flatow EL, Bigliani LU. Surgical treatment of complete acromioclavicular dislocations. Am J Sports Med. 1995;23(3):324-31. https://doi.org/10.1177/036354659502300313.

48. Flint JH, Wade AM, Giuliani J, Rue JP. Defining the terms acute and chronic in orthopaedic sports injuries: a systematic review. Am J Sports Med. 2014;42(1):235-41. https://doi.org/10.1177/0363546513490656.

\section{Publisher's Note}

Springer Nature remains neutral with regard to jurisdictional claims in published maps and institutional affiliations.

Ready to submit your research? Choose BMC and benefit from:

- fast, convenient online submission

- thorough peer review by experienced researchers in your field

- rapid publication on acceptance

- support for research data, including large and complex data types

- gold Open Access which fosters wider collaboration and increased citations

- maximum visibility for your research: over $100 \mathrm{M}$ website views per year

At BMC, research is always in progress.

Learn more biomedcentral.com/submissions 